\section{Antonia Leach}

Leicester College, United Kingdom
2018, Vol. 15 (1), 69-81(138)

revije.ff.uni-lj.si/elope

doi: 10.4312/elope.15.1.69-81

UDC: 821.111.09-311.9Banks I. M.

\title{
Iain M. Banks - Human, Posthuman and Beyond Human
}

\begin{abstract}
Iain M. Banks has been at the forefront of the space opera science fiction scene since the publication of the first Culture novel, Consider Phlebas, in 1987. Upon Banks' death in 2013, the Culture series became a complete body of work. Whilst some criticism has focused on the social and political implications of the Culture universe, little has engaged with the philosophical concepts that underpin it in relation to the current debate regarding our posthuman future. This paper seeks to show how Banks problematises the relationship between the human and posthuman through an exploration of the representation of the posthuman body. Furthermore, it also seeks to address the implications of current concepts of what it means to be human by exploring the relationship between the posthuman and form of Artificial Intelligence that Banks presents. To illustrate these arguments, three Culture texts will be discussed: The Player of Games (1988) Excession (1996), and "The State of the Art" (1989).
\end{abstract}

Keywords: Iain M. Banks; Culture series; science fiction; posthuman; Artificial Intelligence

\section{Iain M. Banks - človeško, postčloveško in onkraj-človeško}

\section{POVZETEK}

Iain M. Banks je že od izida prvega romana iz serije Culture z naslovom Consider Phlebas (1987) eno vodilnih imen znanstvenofantastične vesoljske opere. Po Banksovi smrti 1. 2013 je serija del o nezemeljski civilizaciji Culture postala zaokrožena celota. Večina kritiških obravnav se osredotoča na družbene in politične implikacije te družbe, le malo pa se jih ukvarja s filozofskimi koncepti, ki serijo povezujejo z aktualno debato o postčloveški prihodnosti. Z analizo reprezentacij postčloveškega telesa $\mathrm{v}$ teh delih želim pokazati, na kakšen način Banks problematizira povezavo med človeškim in postčloveškim. V prispevku se z raziskavo odnosa, ki ga Banks vzpostavi med med postčlovekom in umetno inteligenco, dotaknem tudi pomena sodobnih pogledov na to, kaj je človek. Svoja opažanja utemeljujem na treh besedilih iz serije Culture: The Player of Games (1988), Excession (1996) in 'The State of the Art' (1989).

Ključne besede: Iain M. Banks; serija Culture; znanstvena fantastika; postčlovek; umetna inteligenca 


\section{Iain M. Banks - Human, Posthuman and Beyond Human}

\section{Introduction}

Donna Haraway's seminal work "A Cyborg Manifesto" (1991 [1984], 149-81) described the cyborg as "a hybrid of machine and organism". Since the scientific advances of the nineteenth century, people have been able to augment their bodies, and every procedure from the insertion of a pacemaker to genetic selection in embryos permanently alters the human body. In most cases, this is designed to improve upon the 'natural' state of the body. Rosi Bradotti suggests that the continued integration of technology into everyday life will result in the development of a symbiotic relationship between humans and technology, which, in turn, will drive the direction of growth for both $(2013,41)$.

It is easy to see the possibilities of altering the human body through medicine and technology; what is more difficult to perceive is how the relationship between humans and information technology might also create a new vision of the posthuman. Rather than being based on physical augmentation, this vision is predicated on the augmentation of the human mind with computer systems. The current reliance on the internet for finding and sharing information demonstrates a current incarnation of this supplementation. However, as computer programming becomes more complex and user interfaces become subtler, the distinction between user and programme will become less obvious. The current development of Artificial Intelligences (AIs) is constrained by programming limitations, but the complexity of these systems is advancing rapidly. As AIs are developed to replicate human decision-making they may become, over time, able to replicate the human ability to make moral and ethical decisions as well as logical ones.

However, the dystopian potential for this form of posthumanism can be found in William Gibson's Neuromancer (1984), where the distinction between machine and human consciousness appears non-existent. The concept of the convergent progress of man and machine implies that whilst humans have created and developed machines, the process of alteration is occurring in both directions. Addressing this issue, Martin Halliwell and Andy Mousley argue that "in a cybernetic age we have become copies of copies for which the original has been lost" $(2003,162)$, suggesting that these developments are changes that cannot be unmade. Kim Toffoletti argues that "the subject is reformulated through the interfaces and interconnections of technological interaction", implying that what it means to be human must necessarily adapt as our relationship with technology changes $(2007,157)$.

The concept of the posthuman is fluid in nature. Whilst it is often argued that the posthuman age is already here, there seems little consensus as to what actually constitutes the posthuman. Sherryl Vint argues against taking a simplistic view of the posthuman; rather than considering it as simply a state of the physical body, it should be considered as a state following humanism $(2007,101)$. This suggests the consideration of a philosophical approach to posthumanism, rather than an interrogation of the physical impact of technological development on the human body.

Braidotti argues that the scientific and biotechnological advances that are being implemented on the human body have already shifted our understanding of what it means to be human today $(2013,40)$. This also implies a shift in ideas of what can be considered human in the face of physical or genetic alteration, and reasserts some of the basic questions plaguing humanism; what 
does it mean to be human? What constitutes the parameters of humanity? These questions become increasingly difficult to answer with each subtler technological development. If the solution for human self-improvement is the inclusion of technology into the human body, does this inherently create a being less 'human'? And what then can be inferred about the primacy of humanity?

Iain Banks' body of science fiction, known as the Culture series, comprises nine novels and at least two, although more likely three, short stories. ${ }^{1}$ This paper focuses on the Culture novels The Player of Games (1988) and Excession (1996), and the short story "The State of the Art" (1989), all published under Iain Banks' science fiction moniker 'Iain M. Banks'. Set in the far distant future, this series details the interactions of a number of the Culture's citizens, both posthuman and AI. The first section examines the implications of the biological and genetic augmentation of humans, while the second explores the interaction of humans and technology, and the concept of sentience as equating to personhood.

In the essay "A Few Notes on the Culture", Banks outlines some personal beliefs that underpin the development of the Culture as an idea; namely, that "our currently dominant power systems cannot long survive in space", and that a different, more effective type of society would have to develop to support humanity as a space-faring civilization (1994). With such a rich resource detailing the political and social ideas underpinning the texts, it is easy to see why much critical analysis has focused on the social and political structures described in the works. Ronnie Lippens' analysis of the role of technology in the Culture in relation to its utopian structure engages sympathetically with Banks' socialist views, suggesting that "A Few Notes on the Culture" has shaped the criticism that focuses on the author's science fiction (2002). However, Banks also raises questions about the role of the human in this space-faring context, detailing the ability of Culture humans to change sex at will. Rather than considering the implications of this for the individual, the focus is on how this might affect or alter the society as a whole. Similarly, sentient AIs are considered in terms of their role in society and the rights afforded to them, but it is not acknowledged that the concept of equating sentience to personhood raises questions about what it means to be human.

Banks, in developing a hypothetical social and political framework for the future of humanity, also developed a construction of the human and posthuman identity. Through his exploration of biologically and genetically enhanced humans, Banks raises questions about what it means to be human now and what it could mean in the future. The representation of AIs reflects current notions about the potential of technological development, and how this intersects with the evolution of humanity and the development of the posthuman; as Banks states, humanity is "on the way to blurring the boundary between the real and the virtual to the point of irrelevance" (2012). This convergence of the themes of technological advancement, physical augmentation and computer sentience suggests that Banks' Culture series has much to offer a posthuman critical perspective.

\section{The Problematic Posthuman Body}

The Culture society is a vision of a posthuman society. It is based on the combined premise of social enlightenment and technological advancement, and is grounded firmly in the realm of the posthuman by both the biological and physical makeup of its citizens, and the manner in which they interact with technology. By employing physical homogeneity amongst the Culture citizens

Banks did not categorically state that the short story "Descendants" in the short story collection The State of the Art (2010) is set in the Culture universe, although the premise and incorporation of AI make it likely. 
Banks highlights the role of the posthuman body as a factor that supports the social imperative of the Culture. This homogeneity effectively eliminates bodily distinction and difference as a method of social discrimination, advocating equality through sameness. Banks also addresses concepts of human/machine interaction and interdependence, which is significant because the relationship between the two defines the space that the posthuman body occupies; a space that wouldn't exist without the evolution of AIs. Banks also explores the determination of sentience and personhood in the context of AIs, which is reflected as a parallel to contemporary humanity.

Banks states that as a highly advanced society comprised of multiple humanoid species, "virtually everyone in the Culture carries the results of genetic manipulation in every cell of their body; it is arguably the most reliable signifier of Culture status" (1994). This genetic manipulation (or 'genofixing', as Banks called it) has resulted in the Culture species being born with a significantlyhigher-than-human intelligence in addition to many other adaptations, including:

an optimized immune system and enhanced senses, freedom from inheritable diseases or defects, the ability to control their autonomic processes and nervous system (pain can, in effect, be switched off), and to survive and fully recover from wounds which would either kill or permanently mutilate without such genetic tinkering. (Banks 1994)

The results of this genetic alteration are thus presented in terms of the "new-eugeneticist discourse of human improvement", and highlighting the positive aspects of these improvements suggests that this use of genetic manipulation is "comparatively innocent" (Vint 2007, 99).

However innocent this alteration may be considered, Vint clearly identifies these genetic changes as a foundation of the distinction between the human and posthuman body, claiming that "humanoid citizens of the Culture inhabit radically genetically and surgically modified posthuman bodies that are as indestructible as those of video-game heroes" $(2007,79)$. Whilst these genetic alterations are described in terms of their improvement upon a fallible human physicality, as being designed to structurally improve the body, not all alterations can be so easily construed as the result of correcting evolutionary imperfections.

In "The State of the Art", the Culture antagonist Linter describes some of the physical differences between Culture humans and those resembling those of today (described in the series as "humanbasic'). Linter details the physical alterations undertaken to become human, the most prominent of which was the removal of drug glands (Banks 2010,154). These glands, designed to "secrete - on command - mood- and sensory-appreciation-altering compounds into the person's bloodstream", act predominantly as a way of heightening the positive experiences of living (Banks 1994). However, in The Player of Games, the protagonist Gurgeh describes these drugs as comprising:

up to three hundred different compounds of varying degrees of popularity and sophistication; Sharp Blue was one of the least used because it brought no direct pleasure and required considerable concentration to produce. But it was good for games. What seemed complicated became simple [...] A utility drug; an abstraction-modifier; not a sensory enhancer or a sexual stimulant or a physiological booster. (Banks 1989, 9)

Whilst Gurgeh employs this ability to secrete drugs as a method of skill-enhancement, this is described as uncommon among the Culture citizens; where Gurgeh's primary impetus for drugsecretion is a desire to become more competitive, the majority of citizens 'gland' drugs in order to enhance their sense of pleasure. This illustrates that the posthuman body of the Culture citizen 
has been augmented for comfort. In this way the posthuman body appears to have become a vehicle for promoting the political and social structure of the Culture itself.

With advanced AIs in effect running the society, the role of humans has been reduced to engaging in "something indistinguishable from play, or a hobby" (Banks 1994). Whilst each individual augmentation, such as an optimized immune system, clearly resolves some problem experienced by a human, it also promotes a bodily homogeneity. This is most obvious in the Culture-human's ability to change sex at will, with Banks suggesting that:

A society in which it is so easy to change sex will rapidly find out if it is treating one gender better than the other; within the population, over time, there will gradually be greater and greater numbers of the sex it is more rewarding to be, and so pressure for change - within society rather than the individuals - will presumably therefore build up until some form of sexual equality and hence numerical parity is established. (Banks 1994)

In such a society, where everybody is well and has an element of choice in their physical morphology, Vint argues that the Culture has been effective in "eliminating bodily distinctions as a ground for social discrimination" $(2007,87)$.

Whilst this suggests that the posthuman body has become indicative of a level of equality amongst people, it is also indicative of a Cartesian approach to the distinction between mind and body; the essential nature of a person is the mind, with the body occupying the role of a container for this essential nature. In this way, even though the body has developed from the human-basic into the posthuman, the essential nature of the person, the mind, remains human. This concept of the mind as the essence of the person is also shown in the approach taken by the Culture to negate the death of its citizens.

In Excession, Banks describes the lifespan of a Culture human as an "artificially extended threeand-a-half to four centuries of life", indicating that there is an expected end to even this longer life $(1996,81)$. However, in going on to describe the choices that a Culture human can make regarding the end of their life, Banks offers a number of solutions to the concept of death that are available:

They could opt for rejuvenation and/or complete immortality, they could become part of a group mind, they could simply die when the time came, they could transfer out of the Culture altogether, bravely accepting one of the open but essentially inscrutable invitations left by certain Elder civilizations, or they could go into Storage, with whatever revival criterion they desired. (Banks 1981, 81)

This suggests that while death is no longer inevitable to Culture citizens, it is now a choice and one of many that can be made towards the end of a life. In Excession, the character Dajeil opted for storage for both mind and body on the General Systems Vehicle Sleeper Service, an AI ship whose primary function is the storage of citizens who have chosen this method of extending their life. Joseph Norman describes storage as "a kind of suspended animation, similar to the process of cryogenic freezing, where life processes are greatly slowed, but not enough to cause actual death or $[\ldots]$ where life is put on 'pause" $(2013,154)$. Here, Banks offers a new scope for the posthuman; although it is a not necessarily a feature of the posthuman body so much as the Culture society, the premise of a species for whom death is simply an option highlights the posthuman as an improvement upon the contemporary human. 
Whilst the notion of negating death offers a concept of the posthuman as a being that has broken the final barrier of human improvement, it also suggests a shift beyond the position of the living; as a human, the very concept of life is inherently bounded by the inevitability of death. If physical death is not inevitable, then the only possible parameters for an event similar to death is brain-death, and even this is non-fatal for Culture citizens, who are able to 'back up' a copy of their consciousness as digital information.

Here there is an inherent equivalence of 'mind' and 'person'; if a person can be restored from a digital copy of their mind, then the body must be extraneous (or, at least, nonessential) to the innate or essential aspect of the person. In addition to reducing the nature of humanity to the sentience of a person, the ability to 'back-up' the essence of a person as digital information supports Scott Bukatman's assertion that "the proliferation of the technologies dedicated to information and communication comprise an extension, outside the body, of the central nervous system: that elaborate, electrical, message-processing system" $(1993,70)$. This suggests an argument for considering the shift of personhood from biological to digital as simply another stage in the evolution from the human to the posthuman.

The idea of the negation of death as a defining parameter for a living being, in addition to the physical and biological augmentation of the posthuman body, also raises questions about the idea of the human-as-animal in a posthuman setting. In this respect, Gareth Jones and Maja Whitaker suggest that the posthuman body "has moved into an artificial realm, in the sense that the body has been cajoled into functioning in a way in which it would not act apart from this intervention" $(2012,258)$. In "The State of the Art", Banks raises this concept as a dichotomy of artificial and natural, with Linter arguing that the Culture is an unwelcome mutation from the more natural human person, describing the Culture as "the infection [...] We're the ones who are different, we're the self-mutilated, the self-mutated" (Banks 2010, 156). Here Banks highlights the artificial aspect of augmentation, suggesting that whilst biotechnological advancements may offer a method of improvement upon the pre-existing human condition, these improvements may, in themselves, reduce the extent to which the person can be considered human.

Whilst Linter argues against the developments of the Culture by describing them as a form of mutilation, he also argues for contemporary humanity as occupying a position of naturalness, an innate essence of being that defines humanity. According to this view, humans are more natural "because they live the way they have to. We aren't because we live the way we want to" (Banks 2010,156 ). This suggests that the biological constraints placed upon contemporary humanity by the evolutionary process offer them a privileged position from which to live as a 'true' being, and any augmentation or alteration to the bodily construct of the human is reductive to this position.

Whilst ascribing a level of naturalness to contemporary humanity may support the speciesist notion of human superiority, it fails to engage with the evolutionary process that has resulted in humanity as it currently is. Darwin's theory of natural selection is predicated on three main points, although only the first and third are pertinent here:

First, members of a species differ from one another, and this variation is heritable [...] Third, given that not all offspring survive those that do, are, on average, likely to have an anatomy, physiology, or behavior that best prepares them for the demands of the prevailing environment. (Lewin 2005, 18)

The first point highlights Peter Singer's assertion that humanity, in ascribing a privileged position to itself must assume a position of theoretical equality amongst people, as there is no actual 
equality amongst them $(1975,5)$ - after all, the homogenized posthumans of the Culture occupy an oppositional position to the heterogeneous humans of today. The third point argues that those humans that exhibit traits that promote survival in current conditions are the ones most likely to survive, which offers a framework of survival based on adaptability. It also suggests that adaptation must occur as the prevailing conditions alter; therefore, as a newly space-faring species, it is unthinkable to suggest that prevailing conditions have not changed, and that humanity would not adapt to these new conditions in respect to anatomy, physiology or behaviour. Whilst Linter's view supports the humanist idea of the superiority of humanity by ascribing the innate nature of the human to contemporary humanity, its reliance on the idea of 'naturalness' as a superior quality creates a self-reducing theory. As a premise, it relies on disregarding current understanding of contemporary humanity as a product of natural change to discount the validity of potential future changes that could produce the posthuman. This is succinctly highlighted by Diziet Sma's argument against Linter's view of the naturalness of humanity: "They're no more natural than us than an amoeba is more natural than them just because it's cruder" (Banks 2010, 157).

Here, the interaction of each premise offers a glimpse of the problematic relationship presented by Banks between the human and posthuman. Where the augmentation of the posthuman body suggests that the contemporary human body is one to be improved upon, Banks undermines the humanist notion of the primacy of humanity. However, this is also undermined by the positioning of the posthuman body as being outside of humanity; any body which can experience death as a choice rather than an inevitability must exhibit traits that are distinctly inhuman. Where the human body could be ascribed the position of a natural being, which perpetuates the speciesist notion of human primacy, Banks' refusal to ascribe this same process to the posthuman undermines the integrity of the concept of a 'natural' form of humanity at all.

\section{The Posthuman and Artificial Intelligences}

Banks problematises the relationship between the posthuman and AIs by projecting an image of a future where AIs have developed into a species in their own right. The AIs of the Culture are a self-reproducing species that no longer requires the intervention of humanity to achieve progress. They reproduce through a process of growth rather than manufacture, and have developed intelligence far beyond that of their once-dominant human counterparts. In addition, $\mathrm{AI}$ sentience is considered as being of equal value to human sentience in prescribing conditions of personhood in the Culture. By writing the relationship between these two species from a platform of equality, Banks highlights the evolution of AIs as sentient beings as a process that makes the posthuman redundant.

In addition to the relationship between the human and posthuman, Banks also explores contemporary concerns about the future of AI through the relationship between Culture humans and the AIs that, in effect, run the Culture: the Minds. This relationship between the posthuman and technology is, in itself, considered a definitive part of the Culture. Banks argues that at the point that humanity travels in space, it "would no longer be a one-sentience-type species. The future of our species would affect, be affected by and coexist with the future of the AI life-forms we create" (1994). Whilst the concept of what Norman referred to as 'digital souls' has been touched on briefly in relation to the mortality of the posthuman, Banks' exploration of sentience in a technologically advanced society serves to explore contemporary notions of personhood. In Banks' work, a humanist vision of species hierarchy collapses as he explores ideas of the distinction between human and non-human species. 
Banks portrays the functional relationship between AIs and Culture humans as an imbalance of power; whilst he does offer a view of society in which humanity is dependent on computer minds, this is not portrayed as a dystopian vision of a future in which the lowly humans are slaves to omniscient machines (a la The Matrix. 1999). Gavin Miller argues that Culture humans "live in partnership with artificial life forms whose superior intelligence directs a wholly automated economy" $(2007,203)$. Whilst Miller admits here the reliance on artificial minds to ensure the continuance of Culture society, he also fails to adequately portray the scope of the imbalance of power within the Culture between AIs and humans.

The dependency of humans on AIs is given physical incarnation by Banks in the form of the terminal, a pen-shaped device that enables Culture's AIs to keep tabs on their human counterparts. In The Player of Games, terminals are described in terms of safety nets:

A terminal $[\ldots]$ was your link with everybody and everything else in the Culture. With a terminal, you were never more than a question or a shout away from almost anything you wanted to know, or almost any help you could possibly need. There were (true) stories of people falling off cliffs and the terminal relaying their scream in time for a Hub unit to switch to that camera, realise what was happening and displace a drone to catch the faller in mid-air [...] A terminal was safety. (Banks 1989, 84)

Banks here highlights the positive aspects of terminals, describing the protection afforded by these devices and the AI minds that monitor them, and the positive consequences of such constant monitoring. The description emphasises the terminal as a necessary safety net designed to catch and save Culture humans when they make dangerous mistakes.

Banks represents this relationship as one not just of human dependency, but also of AI responsibility, a mirroring of the parent-child relationship that polarizes humans and AIs in terms of independence and autonomy. In "The State of the Art", Linter plays down the terminal's intrusion as "just a formality" (Banks 2010, 153). In contradiction to this, however, it is acknowledged that by refusing to use it there was a risk of leaving the AI ship mind, the General Contact Unit named Arbitrary, feeling responsible should anything untoward happen. This infantilising of the Culture humans is further compounded by Banks' use of fairy-tale rhetoric in describing the role of terminals in the life of Culture humans:

Stories set in the Culture in which Things Went Wrong tended to start with humans losing or forgetting or deliberately leaving behind their terminal. It was a conventional opening, the equivalent of straying off the path in the wild woods in one age, or a car breaking down at night on a lonely road in another. (Banks 1989, 84)

This shows that humans are not only dependent on AIs for their own safety, something they appear incapable of maintaining, but that they also need to be taught this as rhetoric in order that they comprehend the role of AIs in managing human fallibility. Banks shows the Culture human/AI relationship in terms of an inequity of dependence and reliance, rather than one of mutual dependence or symbiosis.

Whilst mutual dependence may be lacking in the relationship between Culture humans and AIs, it is clearly grounded in a consideration of equality between them. As Vint argues, the Culture "is characterized by equality - machine sentience is fully recognized as constituting personhood", suggesting that whilst the AIs of the Culture take responsibility for the safety of their human 
counterparts, this is a mutually agreed state of affairs in which both parties have an equal choice $(2007,79)$. The concept of an AI having to make choices in the context of being considered a person is a theme Banks repeatedly explores: in "The State of the Art", the AI called Arbitrary decides whether or not to allow Linter to remain on Earth, eventually concluding that even though it disagreed with the choice "when I couldn't reasonably decide he was mad - I did what he asked" (Banks 2010, 160).

Banks offers a system of personhood (the Culture's method of equating sentience with personhood) that requires the AI to make moral decisions that coincide with the liberal structure of the Culture, a consideration that is made explicit when the Arbitrary justifies its decision as being "in as close accord with the basic principles of our society as it is within my power to make it" (Banks 2010, 162). Banks presents a structure of equality between humans and AIs based on a mutually subscribed-to moral ideal; that either party is free to make any decision as long as it is within the liberal framework of the Culture societal structure. This constitutes any person having the right to do as they wish, with the caveat that this must not impinge upon another person's right to do the same.

Banks also explores the concept of human/AI equality in "A Few Notes on the Culture", considering the responsibility of society towards the individual, as opposed to the responsibility of the individual towards society (1994). Banks describes a position where "nothing and nobody in the Culture is exploited," and frames a concept of AI non-exploitation:

no machine is exploited, either; the idea here being that any job can be automated in such a way as to ensure that it can be done by a machine well below the level of potential consciousness; what to us would be a stunningly sophisticated computer running a factory (for example) would be looked on by the Culture's AIs as a glorified calculator, and no more exploited than an insect is exploited when it pollinates a fruit tree a human later eats a fruit from. (Banks 1994)

By couching the equality of treatment of humans and AI in terms of non-exploitation, Banks promotes an equality of rights that is not dissimilar to Stringer's anti-speciesist narrative.

This equality of AIs and humans also raises questions about what it means to be human in a Cartesian context. Where the evolution of the posthuman body has adhered to the Cartesian position of the mind as the essential way of defining the person, this needs to be taken into account when considering the idea of equality between AIs and humans. This essentialist construct creates a problematic discourse on the nature of the artificial as human. Descartes' philosophy of the mind as subject and body as object relies on the oppositional nature of the mind as a state of consciousness, and the idea that the "body must be a machine" [original emphasis] (Baker and Morris 1996, 17). Therefore Banks' equated concept of personhood between artificial and biological consciousness undermines the notion, inherent in Descartes' theory, that consciousness and machine are mutually exclusive. This concept is further undermined by Banks' description of the hyper-intelligent Mind AIs that effectively run the Culture:

Minds (sophisticated AIs working largely in hyperspace to take advantage of the higher lightspeed there) bear the same relation to the fabric of the ship as a human brain does to the human body; the Mind is the important bit, and the rest is a life-support and transport system. (Banks 1994) 
If Minds as a whole conform to the idea of Cartesian dualism, should any distinction be drawn between mind/consciousness and body/machine? The inference of Banks' Minds suggests that mind and machine may no longer be mutually exclusive concepts, and that attempting to distinguish in this way is reductive in its humanist construct. By affording primacy to a biological construct of consciousness, the mind-body dualism fails to account for the potential for the development of a truly conscious machine, problematising the concept of the mind as an essential self.

Whilst Banks clearly defines this equality of human and AI in the Culture, this offers an ironic reflection of contemporary humanist speciesism. Where humanism affords primacy to the experience of the human as a rational being, and denotes the non-human experience as irrational or illogical, Banks subverts the notion that rational experience can only be human. The Culture is described as "quite self-consciously rational", and in a society in which equality of personhood is awarded to humans and AIs it is illogical to suggest that only the human half of such a rational society could be consciously rational (Banks 1994). Banks explicitly defines Culture AIs in terms that highlight them as rational beings: "Culture AIs are designed to want to live, to want to experience, to desire to understand, and to find existence and their own thought-processes in some way rewarding, even enjoyable" (Banks 1994). Banks undermines the humanist premise of humans as unique in their rationality, and calls into question the speciesist grounding of this theory; that the human experience should be centred above all else because of the primacy of humanity as a species.

In explicating the scope of AI intellect in relation to that of Culture humans, Banks highlights the humanist notion of the human as the most advanced, rational species as a flawed premise in an ever-evolving society. Banks describes the scope of the General Systems Vehicles as the largest Minds in the Culture:

The GSVs are fast and very large craft, measured in kilometres and inhabited by millions of people and machines. The idea behind them is that they represent the Culture, fully. All that the Culture knows, each GSV knows; anything that can be done anywhere in the Culture can be done within or by any GSV. In terms of both information and technology, they represent a last resort, and act like holographic fragments of the Culture itself, the whole contained within each part. In our terms, the abilities of a GSV are those of - at least - a large state, and arguably a whole planet. (Banks 1994)

In describing the GSVs in terms of their scope in a planetary capacity, Banks highlights the intelligence of these Minds as a conglomeration of every facet of the Culture within one sentience. From the perspective of a GSV, Banks describes Culture humans as having "a status somewhere between passengers, pets and parasites" (1994). Whilst an unflattering description, this highlights the inferiority of humans to the AI Minds that effectively run the Culture, and the inequality of the relationship between the two.

Through this construction of the Culture human/AI relationship, Banks problematises the term 'AI'. Where the initial use of this term in 1955 was to describe the premise of a computer being able to simulate intelligence, Banks extrapolates this notion in the context of continued digital innovations, such as the current development of chatbots designed to interact conversationally with humans. Here Banks offers a view of the future in which digital programmes have become advanced to the point of sentience, and that sentience is recognized as constituting personhood. The equal consideration of these forms of sentience is detailed by the AI drone Mawhrin Skrel in The Player of Games: 
What difference does it make whether a mind's made up of enormous, squidgy, animal cells working at the speed of sound (in air!), or from a glittering nanofoam of reflectors and patterns of holographic coherence, at lightspeed? [...] Each is a machine, each is an organism, each fulfils the same task. Just matter, switching energy of one sort or another. (Banks 1989, 231)

This is an explicit parallel between AI and human minds, compounded by Banks' choice of terminology; to call the AIs 'Minds' is to raise connotations of the biological and organic, which deliberately erases constructs of difference between human and AI consciousness.

Banks has also created reproduction parallels between AIs and humans, detailing the creation of AIs in the Culture as an organic process:

As with all sentient Culture constructs, [the drone's] precise character had not been fully mapped out before its construction, but allowed to develop as the drone's mind was put together. The Culture regarded this unpredictable factor in its production of conscious machines as the price to be paid for individuality. (Banks 1989, 14)

This process of growth serves to highlight the $\mathrm{AI}$ as a separate ontological being, the product of a distinct evolutionary process rather than a predetermined product of a mechanical process. This is further highlighted by Banks' assertion that the Culture Minds have been "designed (by other AIs, for virtually all of the Culture's history)" (1994). In this respect AIs should have the same consideration as other biological species; whilst humans may have initially built them, the AIs now effectively reproduce themselves and should, therefore, be considered an independent species. Furthermore, the integration of the AI technology within the Culture offers a projection of the future in which the posthuman is essentially made redundant by the evolution of an AI species.

\section{Conclusion}

In the Culture series Banks engages with the posthuman debate by adopting a philosophical position that refuses to completely endorse posthumanism. Instead, the extent to which posthumanism relies on essentialist concepts of the human within the humanist debate are explored. By highlighting these problematic issues with the representation of the human/ posthuman relationship, Banks manages to subvert reductive constructs designed to privilege a straightforward narrative of either species as occupying the position of primacy.

Additionally, Banks encases Cartesian dualism within the posthuman subject, suggesting that the posthuman body is nonessential to the posthuman mind, and thus rendering the digital soul as a necessary evolutionary development and an alternative focus for the transition between human and posthuman.

In creating a vision of the AI that is evolved and distinct from humanity, as well as intellectually superior, Banks undermines the Artificial aspect of the AI. How could a word with connotations of imitation and simulation apply to an independent species that has evolved far in excess of human intelligence and moral understanding? There must be a consideration that contemporary innovations in digital technology might one day progress in this direction. To fully comprehend the implications of this, a more considered linguistic approach is necessary to frame the potential directions for this development. Where we might attribute imitative characteristics to AIs, to engage fully with the concept of digital beings that have the sentient scope of Banks' imagined 
Minds, we must develop a language that reinforces the redrawn boundaries of the digital. Instead of AIs, we should be discussing the potential for non-biological sentience.

Furthermore, Banks' vision of the parallel evolution of AI technology and the posthuman fails to engage with current debates regarding whether or not it would be possible for humanity to extend the neurological lifespan to match the extended lifespan already being seen in western populations. Whilst the citizens of the Culture experience a lifespan extended by approximately $400 \%$ that of contemporary humanity, Banks does not address (separately) the extension of capacity. Addressing this concept could, perhaps, offer further insight into the construction of a more equal parallel evolution of human-to-posthuman, and AI.

\section{Acknowledgements}

I owe a debt of gratitude to Dr Scott Freer for his sound advice and support. I would also like to thank Claire Moore, Cathal Farragher and Sarah Farragher for their endless patience and encouragement.

\section{References}

Baker, Gordon, and Katherine Morris. 1996. Descartes' Dualism. London: Routledge.

Banks, Iain M. 1989. The Player of Games. London: Orbit.

—. 1994. "A Few Notes on the Culture." http://www.vavatch.co.uk/books/banks/cultnote.htm.

—. 1996. Excession. London: Orbit.

-. 2010. "The State of the Art", in The State of the Art, 97-203. London: Orbit.

Bradotti, Rosie. 2013. The Posthuman. Cambridge: Polity.

Bukatman, Scott. 1993. Terminal Identity: The Virtual Subject in Postmodern Science Fiction. Durham, NC: Duke University Press.

Halliwell, Martin, and Andy Mousley. 2003. Critical Humanisms: Humanist/Anti-Humanist Dialogues. Edinburgh: Edinburgh University Press.

Haraway, Donna. 1991. Simians, Cyborgs and Women: The Reinvention of Nature. Oxon: Routledge.

Jones, Gareth, and Maja Whitaker. 2012. “Transforming the Human Body.” In Beyond Human: From Animality to Transhumanism, edited by Charlie Blake, Claire Molloy, and Steven Shakespeare, 254-79. London: Continuum.

Lewin, Roger. 2005. Human Evolution: An Illustrated Introduction, 5th ed. Oxford: Blackwell.

Lippens, Ronnie. 2002. "Imachinations of Peace: Scientifictions of Peace in Iain M. Banks's The Player of Games." Utopian Studies 13 (1): 135-47.

Miller, Gavin. 2007. "Iain (M.) Banks: Utopia, Nationalism and the Posthuman.” In The Edinburgh Companion to Contemporary Scottish Literature, edited by Berthold Schoene, 202-9. Edinburgh: Edinburgh University Press.

Norman, Joseph. 2013. "Digital Souls and Virtual Afterlives in the Culture Series." In The Transgressive Iain Banks: Essays on a Writer Beyond Borders, edited by Catherine Cox and Martyn Colebrook, 150-64. Jefferson: McFarland \& Company.

Orbit Books. 2012. "An Interview with Iain M. Banks on the 25th Anniversary of the Culture." http://www. orbitbooks.net/interview/iain-m-banks-on-the-25th-anniversary-of-the-culture/. 
Singer, Peter. 1975. Animal Liberation. Wellingborough: Thorsons.

Toffoletti, Kim. 2007. Cyborgs and Barbie Dolls: Feminism, Popular Culture and the Posthuman Body. London: I.B Tauris.

Vint, Sherryl. 2007. "Iain M. Banks: The Culture-al Body." In Bodies of Tomorrow - Technology, Subjectivity, Science Fiction, edited by Sherryl Vint, 79-101. Toronto: University of Toronto Press. https://doi. org/10.3138/9781442684072. 